\title{
Characteristics of Strategic Management Research of Chinese Enterprises - From Perspective of Management Knowledge
}

\author{
Zhou Yu \\ Business School, Hohai University, Nanjing, 211100, China
}

Keywords: strategic management; Chinese traditional strategic thoughts; management innovation

\begin{abstract}
As Chinese indigenous management research gradually got acknowledged, high-quality research is called on both theoretically and practically. From two types of management knowledge, this paper tries to explore some characteristics of strategic management practice of Chinese enterprises. Under the resourceful tendency of Chinese traditional strategic thoughts, this paper probes into the implicit characteristics of strategic content, and cultural enlightenment in strategic implementation. China's own indigenous strategic management theories should be built up soon.
\end{abstract}

\section{Introduction}

Transformation of Chinese market economy is gradually deepened since reform and opening up to outside during which Chinese enterprises acquired fast growth. China was not considered to have modern enterprises in early 1980s. Today, lots of considerable size, competitive enterprises have become powerful support of China's economic growth and social development. From "Fortune" Global 500, we can see Chinese enterprises are growing with an amazing speed. In 1998, only 8 Chinese companies were listed in this authoritative ranking. 10 years later, 43 entered the club; 2015 there have been 106, accounting for 21.2 percent, further shortens the gap with the US that has 128 listed in the same year. However, compared with those listed of developed countries, nature of Chinese enterprises has no qualitative change during these years: many of them are solely state-owned or state-holding and in heavy industry. Though Chinese enterprises already covered nearly 30 industries, but mining and oil production, banking, metal products etc accounted for 34\%. American enterprises are virtually in all industries. It can be seen that Chinese enterprises in the world economy being still in early growing stage, lack international competitiveness. They need to maintain fast growth and enhance competitiveness worldwide.

Looking at these Chinese outstanding enterprises, we find a successful enterprise always accompanies with an equally acclaimed leader. With western management system and modern transformation of Chinese traditional management thoughts, these outstanding entrepreneurs found a way to manage their enterprises and have made remarkable achievements. Management innovation of these enterprises and entrepreneurs has attracted much attention, whose experiences have been preliminary summarized. But we still urgently needs further theoretical research and practical exploration to form scientific knowledge based on it. With Chinese enterprises becoming powerful, we have gradually accumulated experience in the practice to lay a solid foundation for Chinese management theory construction.

Compared with outstanding enterprises founded before 1950 in US, development process of Chinese enterprises are not the same. Founders of Chinese fast growing enterprises were more dependent on Chinese traditional management thoughts at initial stage of their business. Strategic thinking contained in Chinese traditional statecraft influenced them. Their own aspirations evolved into great ideas of enterprises. With study of western strategic management theories, conceptions that can at best be regarded as strategic thinking evolved and developed into enterprise strategies. In this evolution process, it truly is integrated use of Western strategic management theories and Chinese traditional strategic thoughts. For native Chinese entrepreneurs, when they practice western strategic management theories, it is natural to accept traditional Chinese strategic thoughts, making its strategy practice with its own unique performance. Under this view, we focus our attention on Chinese enterprises and entrepreneurs' strategies, trying to explore some features of strategic 
management under Chinese context.

\section{Two Types of Management Knowledge and Traditional Strategic Thoughts}

Current global management knowledge is mostly developed in the United States of American (excluding Japan), contributed by its native scholars. With Chinese economic rising, its native management research has gradually been recognized as a "legitimate" and field of study with great potential in the world over the past decade (Tsui etc, 2011). Chinese scholars home (Chen, 2014) and abroad (Li, 2013) have brought forward explorations on how to establish high level Chinese indigenous management research. When we turn to Chinese strategic management research, we find its indigenous and contextual discussions have also come under public attention (Wu, 2010; Wei etc, 2014). However, most current research in China is still to checkout existing management theories which are fully established on developed western countries' enterprises (Jia, 2011). To establish Chinese own management theory system is still just fine expectation.

Mizoquchi, Japanese scholar of Chinese thoughts advocated completely abandon the world monism value of "western-centered", looked at the East and West in stand of equal principle and pluralism world, and found out Chinese inherent principles from Chinese history. To get out binding of western management theory universality, $\mathrm{HE(2009)}$ raised that Chinese management innovation is culture agitation of modern western management theories and Chinese traditional management thoughts, and eventually will construct a new management culture, enriching the global management knowledge. This viewpoint founded the basic angle here to observe strategic management characteristics of Chinese enterprises, i.e strategic management practice innovation of Chinese enterprises shall base on modern western strategic management theories, but also cannot ignore the impact of traditional strategic thoughts.

Based on US business management practice, current western system of strategic management theories was built up since 1960s. Strategy means decision of long-term goals and a series of actions taken and allocation of resources needed to realize those goals (Chandler, 1962). Strategic management takes enterprise as analysis unit, studying how to help enterprise build its competitive advantage and maintain a sustainable competitive advantage. Enterprise strategy pays close attention to long-term arrangement of product and market selection (Ansoff, 1965), focusing on industry position (Porter, 1980), enterprise resources (Barney, 1991) and capabilities (Hamel etc, 1990; Teece, 1997). Under SWOT framework, strategy is regarded as match of opportunities and threats caused by external environment enterprise facing, with strengths and weakness of its internal resources and capabilities owned.

Strategic, literally can be interpreted as long-term, systematic, looking far and aiming high under a general view of whole situation. Thus strategic management can be understood as long term and systematic management thoughts. Chinese traditional management thoughts take statecraft as cultural pattern, serving for the country's long-term stability. No matter ideal society of Confucian school's "affluent society", "great harmony world", Taoist school's "a small utopian society", Legalist school's "society of security," or Mohist school's "the world is one family", all shows the state's pursuit of sustainable development. Statecraft contains a wealth of "Grand Strategy" thoughts (Niu, 2005). Interpreting strategic management in this way, traditional Chinese governance thoughts contains a wealth of strategic thoughts.

Chinese traditional management thoughts are generally considered to be formed simultaneously with Chinese traditional culture. Chinese traditional management thoughts which embodied statecraft, went through infancy of Xia, Shang and Zhou, moved to development stage of Spring and Autumn period and Warring States period, matured in Qin and Han dynasties, eventually formed Chinese ancient mainstream management thoughts cored with "Confucian school doctrine and supported by doctrine of Taoist and Legalist" (He, 2001). Continuation of the feudal civilization also contained a continuation of Chinese traditional management thoughts, providing a valuable resource to explore knowledge of traditional strategic thoughts. Today, outstanding Chinese entrepreneurs they absorb essence of traditional strategic thoughts, reform and apply them to business management. Wisdom of traditional thoughts gains modern management significance and 
produces positive effect in business practice.

\section{Resourcefulness Tendency of Chinese Enterprise Strategic Management}

Resourcefulness is scheme, political trickery- Jiang Taigong named it deception and Sun $\mathrm{Zi}$ called it cunning; that is modern astuteness and resourcefulness (Niu, 2003). Chinese traditional resourcefulness thoughts had formed a knowledge system. It is the ideological system to deal with military struggle and state running and management. In Chinese culture history, "Run the country well and make the people peace and security, to live, to plan" as the basic contents of resourceful wisdom occupied the mainstream concepts of cultural forms for a long period of time. Chinese traditional management thoughts developed vigorously by implanting in statecraft and resourceful thoughts of all classes of authors, the ancient philosophers. From the very beginning, Chinese traditional management thoughts had a strong tendency of resourcefulness.

Resourceful tendency refers that statecraft is carried out completely centering on resourceful core, and statecraft services for resourcefulness both in structure and function (Wu, 1993). Due to statecraft (Knowledge of Monarch game) as the core part, basic trend of resourceful culture is determined. As a core component of traditional management thoughts, Chinese traditional strategic thoughts inevitably exhibit the tendency of resourcefulness, as well as behaviors under the guidance of this knowledge.

Resourcefulness deeply influence management behaviors of Chinese entrepreneurs, which makes native Chinese enterprise strategies inseparable with resourcefulness. Resourcefulness thoughts provide a unique management behavior logic for business activities. Enterprise resourcefulness is direct interest-competed behavior that seeks interest re-segmentation and conversion by means of wisdom battle. Resourcefulness of enterprise management practice is a development tendency that appears in its business activities, which focuses on core of resourceful operation logic. This tendency becomes more prominent in dealing with strategic management issues. Resourcefulness application in the enterprise includes roles of internal management and external market competition. Since resourcefulness application uses intelligence replacing open competition, it is often away from the institution and regulation, ultimately goes against the long-term demanding. Therefore, improper use of resourcefulness, even strategic management covered with the resourceful tendency shall bring enterprises and society negative impact.

Frequently occurring commercial wars of Chinese enterprises are just cases of improper use of resourcefulness, such as the typical household appliances industry. Price war of TV industry happens again and again between Changhong and other domestic color TV giants Konka, TCL etc; in air-conditioning industry, there is price competition among Chunlan, Rowa, Changhong, Galanz everywhere. Competitive behaviors of these enterprises clearly display the nature of resourcefulness. Enterprise tactical actions pursue short-term interests, which often seeks to zero game outcome. The price war hurt the vitality of China's color TV industry. Sales below cost, the abnormal competitive manner violates market economy rationality. Changhong failed to keep market leader position. Foreign brands still win in high-tech products in Chinese market.

\section{Implicit Characteristics of Chinese Enterprise Strategy Content}

With resourceful tendency of Chinese enterprise strategic management, as idea source of dealing with competitive strategy issues, resourcefulness plays a non ignorable role. Enterprise strategy can be fine planed (Ansoff, 1965), can be generated by progressing gradually and logically (Quinn, 1987) or be process of continuous learning and acting according to circumstance (Mintzberg, 1991). Porter (1980) argued each company has both implicit and explicit competitive strategy. Most Chinese native enterprise strategies show implicit characteristics. Implicit strategy as a strategic process is opposite to explicit strategy. Strategic subject does not lay down clear strategy, but there must be existence of some kind of intent or order that keeps cognition and actions consistent. Implicit strategy is strategic intent understanding and cooperative effect process of strategic actions by all sectors of enterprise. 
Strategic management of Chinese enterprises has both explicit and implicit behaviors. Western strategic knowledge plays a role in explicit way, and resourcefulness thoughts have impact in implicit way. Implicit strategy has many characteristics like experience-oriented, difficult to express, seeking innovative, suitable for high uncertainty environment, valuable and difficult to study etc. Implicit strategy may appear at any time anywhere in the organization. Some actions will encourage coordination among different people and focus on a strategic theme. When strategic intent gradually being recognized, it will spread in the organization. The process of spread can be no consciousness, and it can be no control intervention too.

Many enterprises’ practices home and abroad embody implicit strategy thoughts, such as Honda motorcycles overseas expansion. When Honda tried to explore American motorcycle market in 1950s and 1960s, it faced dismal sales performance in the beginning, but gained unexpected success in 50CC ultra-scooter, accounted for more than half of the US motorcycle market share at last. Honda motorcycle market development manager said: "In fact, we have not developed any strategy. We just want to know if we can sell products in US market." No formal strategic plan was made before Honda entered US motorcycle market. It went by fuzzy strategy constantly adjusted according to market reaction.

On developing path of Chinese outstanding enterprises, strategy often gradually moves to explicit from implicit. For example, Huawei's early strategy forming wholly relied on the strategic wisdom of the entrepreneur. Huawei's strategy is actually REN's personal strategy. This has fully demonstrated implicit characteristics of Huawei's strategies in its beginning. It has strong sense of ruling of man. Haier's strategies now have clearly developed into five stages: famous brand, diversification, internationalization, global famous brand and network strategy. At beginning, Haier had no clear strategic vision. During time of the seller's market when commodity was in short supply, Haier established its guiding ideology that quality is enterprise's life through the event of "smashing 76 refrigerators". ZHANG first put forward the concept of quality management, then guided employees to agree and accept this idea, and late transformed into the common spirit of the whole company. Advance awareness of quality helped Haier win the trust of consumers. Haier opened up the market, and eventually established an enterprise as domestic famous brand reputation. From the initial concept of high quality emphasis, then development to famous brand strategy and then global famous brand strategy, this is just the developing process of enterprise strategy moving from implicit to explicit.

\section{Culture Enlightenment of Chinese Enterprise Strategy Implementation}

Highlight of cultural enlightenment function is an important feature of Chinese ancient state governance. "Three classes and Eight orders" in "The Great Learning" and thus resulting Confucian school governing model of "Virtue rule enlightenment, cultivate ones moral character and manage state affairs"(He, 2001), are the base of cultural enlightenment proposed in this paper. Ancient management thoughts of Confucian school in the Pre-Qin period, intention of cultural enlightenment refers to governing bodies, they cultivating morality through "Benevolence" learning, to improve personal moral character, and thus set an example, personally practice such morality, educate and influence others. They regularize life according to Benevolence, to achieve the goal of "regulate family proper, maintain the state stable, make world peace".

Under continuous impact of management, Chinese management development does not separate space continuation and time succession, which achieves management harmony of past and present. Thus, current Chinese business management still has a strong cultural enlightenment function features, and it is the guarantee of enterprise strategy implementation. The only difference is the "Benevolence" as the core of the moral culture has been replaced by the core values of modern business management. Direct object of cultural enlightenment becomes establishment of enterprise competitive advantage. In the process of enterprise strategy implementation, it highlights cultural enlightenment function mainly in the following three aspects: First, main components of enterprise strategy, such as enterprise vision etc. have become core elements of corporate culture. Secondly, most of the core elements of enterprise culture are proposed by entrepreneurs. Thirdly, by means of 
cultural enlightenment function, on the one hand enterprise culture becomes shared values of majority employees, gaining standardization and regulating self-discipline; on the other hand, institutionalized core elements of enterprise culture become external behavior norms of employees, i.e heteronomy effect. Strategy implementation eventually evolved into unity of self and hetero organization.

We take Haier and Huawei as example, study the important role of cultural enlightenment during strategic implementation. Haier is a typical culture enterprise. ZHANG said: "Enterprise without culture means no soul." Haier culture has formed a system of surface material culture, middle system and behavior culture and core layer values. ZHANG sees himself as Haier's priest, who continues preaching, enables employees accept enterprise culture, combines embodiment of his own values and realization of enterprise goals. Haier culture reflects strong personal characteristics of ZHANG's thoughts. It can be said that culture core is ZHANG's own management philosophy. Combination of culture and management system is characteristics of Haier management mode: culture implanted in the system, system displaying culture. Haier's "OEC Management Method", "Integrating Order (Customer Demand) with Employee" etc, all are Haier means of ensuring implementation of strategy.

REN said: "Resources will be exhausted, only culture survives". In the past, Huawei management characteristics were "quasi-military management model", "absolute obedience management atmosphere" etc, which deeply reflected "rule of man". In 1998, Huawei promulgated "Huawei Basic Norm" which is key link of REN's management thoughts and core values. Corporate culture is not generated by democracy. It is destined with a distinctive boss character. The thought level of the entrepreneur determines the height of the enterprise culture. REN's thoughts determine Huawei's culture. Later Huawei implemented professional management and introduced IBM process management, carrying out reform of business process and management system to enhance Huawei's competitiveness. From the "rule of man" to institutionalized "rule by law", REN's eventual pursuit is to reshape advanced enterprise culture, form a double helix of people and system, finally achieve "management by noninterference".

\section{Conclusion}

Chinese enterprise strategy matches Chinese context particularity and the history. It creates its own unique way in practice. If only observing it from modern western strategic review, it is difficult to avoid criticism of Chinese enterprises having no strategy, poor strategy or strategic confusion. As a country with 5000 years splendid civilization, it is impossible for current Chinese enterprise strategy to separate influence from traditional culture continuation. These features mentioned above cannot be completely abandoned. On the other hand, we should also see the management foundation of ancient Chinese authoritarian rule of man embedded in the strategic management resourcefulness tendency, and implicit strategic content and cultural enlightenment of strategic implementation. Nearly 4 decades past since reform and opening up, Chinese enterprises led by outstanding entrepreneurs experienced development miracle from scratch, from small to large and from weak and strong. An outstanding entrepreneur with excellent personal qualities plays a powerful role in this developing process. But the shadow of traditional rule of man still remains in many enterprises today, which cannot be ignored. To some extent, this will hinder enterprises to embark on or to continue rapid growing. Attitudes of how entrepreneurs treat influence of traditional rule of man, whether they can go out of its residue and practice modern management theories, this is the inevitable challenge for current enterprises on their way to everlasting sustainable development. In order to maintain the rapid growing of Chinese enterprises in the highly volatile market environment, we urgently need to absorb western scientific strategic management theories, and combine modern conversion of traditional Chinese strategic thoughts together. We need to make this integration innovation, eventually establish indigenous strategic management theories of Chinese enterprises, which shall satisfy the requirements of nowadays. 


\section{Acknowledgement}

This research was supported by the Fundamental Research Funds for the Central Universities under grant No. 26120112011 B09814 \& No. $26120132013 B 12814$.

\section{References}

[1] TSUI, A.S. etc. 2011. Management and building theory: The strategies of research on Chinese native management, Journal of Chongqing University (Social Science Edition), 17(4): 1-7.

[2] JIA, L.D., etc. 2011. Chinese context and theoretical contributions to management and organization research: A three-decade review, Management and Organization Review.

[3] WU, Y.J. 2010. The recent development of strategic management theories in China, Chinese Journal of Management, 7(11): 1692-1703.

[4] HE, S.L., etc. 2009. Management innovation research on Chinese enterprises: Form the perspective of western management theories and Chinese traditional management thoughts, The Thirteenth World Management Forum and Oriental Management Forum, Nanjing, Oct.30-Nov.1. 